\title{
Aspectos dendrológicos de espécies arbóreas da Caatinga
}

\section{Dendrological aspects of tree species from the Caatinga}

Thiago da Silva Medeiros ${ }^{1}$, Cheila Deisy Ferreira ${ }^{2 *}$, Antonio Lucineudo de Oliveira Freire ${ }^{2}$, Eder Ferreira Arriel ${ }^{2}$, Ivonete Alves Bakke ${ }^{2}$

\begin{abstract}
RESUMO
Objetivou-se descrever as características macromorfológicas detalhadas de indivíduos adultos e de estruturas reprodutivas de três espécies arbóreas da Caatinga. Foram selecionados 20 indivíduos adultos de cada espécie em um fragmento de vegetação nativa de caatinga na Fazenda Experimental Nupeárido CSTR/UFCG. As três espécies desta pesquisa (Anadenanthera colubrina (Benth.) Brenan, Cenostigma nordestinum (Tul.) Gagnon \& G. P. Lewis and Mimosa tenuiflora (Willd.) Poir.), são caducifólias e pertencem à família botânica Fabaceae. A espécie A. colubrina possui fuste reto, cilíndrico, base sem saliências (reta), raízes subterrâneas, a casca morta acinzentada, com estrias e grandes acúleos, enquanto que $C$. nordestinum e M. tenuiflora apresentam fustes na maioria dos indivíduos ramificados, retos e/ou inclinados, sem saliências, sendo que a casca morta da primeira possui coloração cinza claro, de aspecto áspero, lenticelas e desprendimento em placas; e a casca morta da segunda espécie possui coloração variando de amarronzada a castanho escura, com textura áspera ou reticulada, e presença de inúmeros acúleos pequenos e pontiagudos, desprendendo-se em fissuras longitudinais.
\end{abstract}

Palavras-chave: Floresta tropical seca; Morfologia vegetal; Dendrologia florestal.

\begin{abstract}
The objective was to describe the detailed macromorphological characteristics of adult individuals and reproductive structures of three Caatinga tree species. Twenty adult individuals of each species were selected in a fragment of native caatinga vegetation at the Fazenda Experimental Nupeárido CSTR/UFCG. The three species of this research (Anadenanthera colubrina (Benth.) Brenan, Cenostigma nordestinum (Tul.) Gagnon \& G. P. Lewis and Mimosa tenuiflora (Willd.) Poir.), are deciduous and belong to the botanical family Fabaceae. The species A. colubrina has a straight, cylindrical stem, base without projections (straight), underground roots, grayish dead bark, with striations and large aculeus, while $C$. nordestinum and M. tenuiflora have stem in most individuals branched, straight and/or inclined, without projections, and the bark of the first has a light gray color, with rough aspect, lenticels and detachment in plates, while the bark of the second has a color ranging from brownish to dark brown, with rough or reticulated texture, and presence of numerous small and pointed aculeles and detachment in longitudinal fissures.
\end{abstract}

Keywords: Tropical dry forest; Plant morphology; Forest dendrology.

\footnotetext{
${ }^{1}$ Discente do Curso de Engenharia Florestal da Universidade Federal de Campina Grande.

2 Professores Doutores do Curso de Engenharia Florestal da Universidade Federal de Campina Grande.

* cheila.deisy@professor.ufcg.edu.br
} 


\section{INTRODUÇÃO}

Os países tropicais são detentores de uma vasta biodiversidade florística, e o Brasil em especial por fazer parte do seu território seis diferentes Biomas. Entre estes encontrase o Bioma Caatinga, que de acordo com o MMA (2020), é exclusivamente brasileiro, situado na região semiárida e se estende por todos os estados do Nordeste e norte de Minas Gerais e, de todas as regiões semiáridas do planeta, a Caatinga é a mais rica em biodiversidade.

Contudo, mesmo com toda essa biodiversidade, ainda é o bioma menos estudado e conhecido, e por consequência, ocorre a subutilização dos produtos e serviços advindos das florestas. A exploração de maneira não sustentável dos remanescentes florestais da Caatinga tem causado prejuízos ao meio ambiente como um todo, como muitas áreas degradadas e ou até mesmo desertificadas. Assim, acredita-se que o conhecimento integral de uma floresta é um pré-requisito para a prática do manejo florestal sustentável.

Sabe-se que os ecossistemas florestais naturais são complexos, tendo aspectos relacionados a solo, clima, fauna e vegetação. E quando se trata sobre a vegetação da caatinga, ocorre variação em formas, hábitos, de acordo com suas diferentes fitofisionomias. Quanto aos hábitos, as espécies que compõem o componente arbóreo são especialmente importantes, pois os mesmos são fontes do principal produto explorado das florestas, a madeira.

Diante dessa variação em número de espécie em diferentes fitofisionomias da caatinga, a correta identificação em campo torna-se um mecanismo importante em estudos de inventário, estrutura fitossociológica e florística da vegetação arbórea. Nesta perspectiva, Marchiori (1995) fala sobre a Dendrologia, que é ciência que tem como objetivo estudar as árvores, e trata tanto da identificação, importância e distribuição geográfica, desempenhando assim um papel fundamental como uma ciência base para ciência florestal, especialmente, a silvicultura.

Conforme o autor acima citado, em levantamentos de campo como inventários florestais, a dendrologia oferece vantagens práticas em relação à identificação botânica tradicional, pois utiliza-se de características de fácil reconhecimento e de presença constante nas árvores. Dentre essas características podem ser citados aspectos da casca, porte, forma da copa e do tronco, exsudações, presença de espinhos ou acúleos, entre 
outras. Assim, para indivíduos mortos, sem folhas, flores e frutos é possível a identificação.

Para Candido et al. (2019), essa vantagem dar-se-á porque a dendrologia se fundamenta em características macromorfológicas, simples de serem visualizadas e não dependem do período de floração e/ou frutificação das espécies. E as chaves de identificação dendrológica possibilitam uma rápida individualização desses caracteres, facilitando e o trabalho de reconhecimento em campo de determinada espécie.

Os objetivos desta pesquisa foram descrever de forma detalhada os caracteres dendrológicos de indivíduos adultos e estruturas reprodutivas Anadenanthera colubrina (Benth.) Brenan, Cenostigma pyramidale (Tul.) Gagnon \& G.P. Lewis. e Mimosa tenuiflora (Willd.) Poir, e à elaboração de chaves de identificação visando facilitar o reconhecimento destas espécies em campo.

\section{MATERIAIS E MÉTODOS}

A coleta de dados em campo foi conduzida em um fragmento de vegetação nativa de Caatinga localizado na Fazenda Experimental Nupeárido (Núcleo de Pesquisas para o Semiárido) pertencente ao Centro de Saúde e Tecnologia Rural da Universidade Federal de Campina Grande, na cidade Patos-PB (0705’10” N; 37¹5’43” O).

Para a descrição morfológica vegetativa de indivíduos de A. colubrina, $C$. pyramidale e $M$. tenuiflora, foram realizadas buscas exploratórias no fragmento de vegetação nativa de caatinga apenas no período seco (outubro a dezembro/2020), as coletas no período chuvoso da região foram realizadas a partir de março/2021.

As coletas de materiais botânicos para comparação com materiais depositados no Herbário CSTR/UFCG afim de confirmação da identificação de cada espécie, foram realizadas a partir de março/2021, com intuito de se obter indivíduos com material reprodutivo. O material vegetal coletado dos indivíduos selecionados das três espécies foi caracterizado em campo e no Laboratório de Dendrologia do CSTR de acordo com Marchiori (1995, 2004).

Para as avaliações dendrométricas foram mensurados 20 indivíduos de cada espécie estudada, onde se avaliou a Circunferência à Altura do Peito (CAP) com auxílio de uma fita métrica em centímetros e Altura da árvore em metros, realizada com uma 
régua graduada, segundo as recomendações da Rede de Manejo Florestal da Caatinga (2005).

Para as árvores com apenas um fuste foram calculados Diâmetro à Altura do Peito (DAP), e para as árvores com dois ou mais fustes foram calculados o Diâmetro Equivalente $\left(\mathrm{d}_{\mathrm{eq}}\right)$ (SOARES et al., 2006). Em seguida, os dados de DAP, altura da árvore e biometria de frutos e sementes foram organizados em planilhas e submetidos à estatística descritiva utilizando-se os Microsoft Excel (2016) e Software BioStat 5.0 (2008). Além disso, foram confeccionadas figuras em forma de pranchas com imagens obtidas em campo e em laboratório das principais características dendrológicas das três espécies, com o auxílio de uma câmera fotográfica digital.

A elaboração da chave dendrológica foi realizada conforme Cândido et al. (2019), onde se apresentaram apenas as características macromorfológicas vegetativas que melhor distinguiram os táxons.

\section{RESULTADOS E DISCUSSÃO}

Sobre a correta identificação das espécies, a princípio acreditava-se que os indivíduos encontrados na área de estudo pertenciam à espécie Cenostigma pyramidale (Tul.) Gagnon \& G. P. Lewis. No entanto, após a confirmação em herbário, constatou-se que se trata da espécie Cenostigma nordestinum Gagnon \& G.P. Lewis. e, dessa forma, apenas essa última espécie será mencionada. Quanto às outras duas espécies estudadas, permaneceram as mesmas após confirmação.

As três espécies fontes desta pesquisa, como A. colubrina, $C$. nordestinum e $M$. tenuiflora, podem ser encontradas de acordo com local de ocorrência com hábito de arbusto ou árvore e à família botânica Fabaceae, uma importante família para o Bioma Caatinga, considerando os aspectos de diversidade, econômicos e ecológicos. De acordo com o site Flora do Brasil (2020), essas espécies são nativas, porém não endêmicas do Brasil. Segundo a mesma fonte, as três espécies possuem distribuição geográfica comum, o Bioma Caatinga, ocorrendo em todos os estados da região do Nordeste do Brasil. Contudo, as espécies A. colubrina e $M$. tenuiflora também já tiveram suas ocorrências registradas para o Bioma Cerrado, enquanto, que a $C$. nordestinum para o Bioma Amazônico. 
A espécie A. colubrina na caatinga desenvolve-se como uma árvore de grande porte, com indivíduos podendo atingir altura maior que $10 \mathrm{~m}$, fuste reto e cilíndrico. Possui copa de formato umbeliforme, de divisão simples, ramificação simpodial e com baixa densidade, permitindo boa visibilidade entre ela, denominada paucifoliada. Essa espécie, de modo geral, não perde totalmente suas folhas durante o período seco da região (julho a dezembro) (Figura 1 A e B), característica que a inclui no grupo das espécies perenes ou semi-caducifólia, a depender do local de ocorrência, assim como já relatado por Carvalho (2002).

Em relação às outras duas espécies $C$. nordestinum e $M$. tenuiflora, desenvolvemse de maneira semelhante em áreas de caatinga, sendo arbustos ou árvores de pequeno a médio porte, com indivíduos com altura de até $6 \mathrm{~m}$, e com fustes na maioria dos indivíduos ramificados, retos e/ou inclinados. As copas possuem formatos variados, desde globosa a irregular, com divisão simples, baixa densidade, possivelmente, devido à ramificação dos fustes (Figuras 1 C, D, E e F). Ainda nessas figuras, obtidas nos meses de setembro e novembro de 2020, meses compreendidos entre o período seco da região de estudo, observa-se a completa abscisão foliar, restando apenas os galhos desnudos para a $C$. nordestinum e os galhos desnudos e flores para M. tenuiflora. Já no mês de março de 2021 (período chuvoso), observam-se as copas com completa brotação das folhas. 
Figura 1 - Aspectos macromorfológicos do fuste e da copa de indivíduos adultos das espécies Anadenanthera colubrina (Vell.) Brenan (A e B), Cenostigma nordestinum Gagnon \& G.P. Lewis. (C e D) e Mimosa tenuiflora (Willd.) Poir (E e F), ocorrentes em fragmento de Caatinga, Paraíba, Brasil.
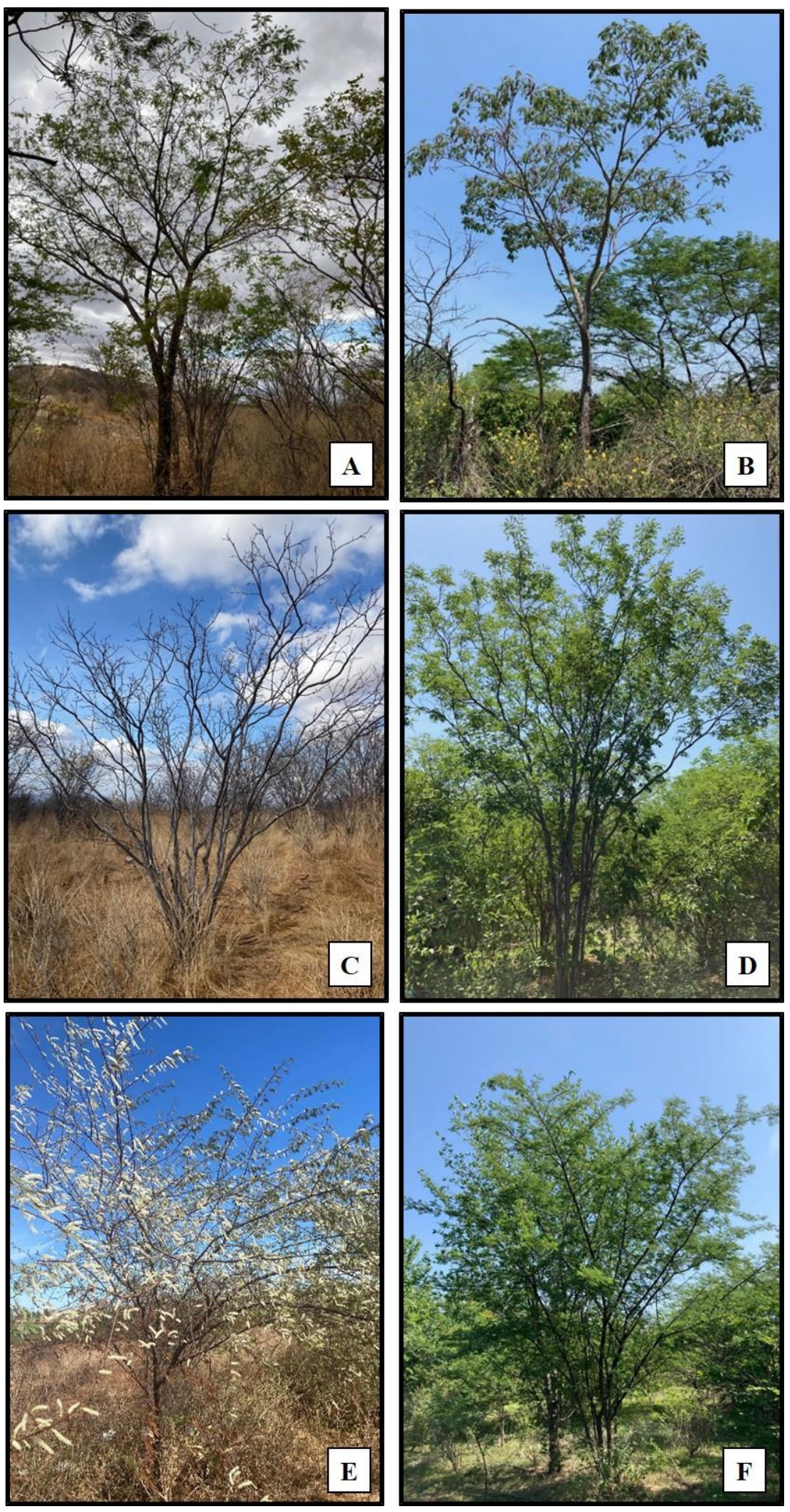
Quanto à perenidade das folhas, essa observação sobre os períodos de perda e brotação, correlacionando com a precipitação, confirma a inclusão dessas duas espécies na categoria de espécies caducifólias.

O fato da espécie Mimosa tenuiflora (Willd.) Poir. ter sua floração no período de maior escassez de água, sendo este o período marcado também pela diminuição de alimentos para fauna e insetos, principalmente, as abelhas, é de extrema importância ecológica, a qual pode ser estendida também para economia, pois assegura a produção de mel durante todo ano.

Quanto às variáveis dendrométricas, observa-se na Tabela 1 a análise estatística descritiva dos dados, sendo possível constatar que a espécie A. colubrina apresentou os maiores valores em altura, DAP e menor número de bifurcações no fuste dos indivíduos amostrados, quando comparada a $C$. nordestinum e M. tenuiflora.

Tabela 1 - Estatística descritiva das variáveis dendrométricas Diâmetro à Altura do Peito - DAP (cm) e Altura da árvore (m) de indivíduos adultos de Anadenanthera colubrina (Vell.) Brenan, Cenostigma nordestinum (Tul.) Gagnon \& G. P. Lewis e Mimosa tenuiflora (Willd.) Poir, ocorrentes em fragmento de Caatinga, Paraíba, Brasil.

\begin{tabular}{|c|c|c|c|c|c|c|}
\hline \multirow[b]{2}{*}{ PARÂMETROS } & \multicolumn{2}{|c|}{ A. colubrina } & \multicolumn{2}{|c|}{ C. nordestinum } & \multicolumn{2}{|c|}{ M. tenuiflora } \\
\hline & $\begin{array}{c}\text { Altura } \\
(\mathbf{m})\end{array}$ & $\begin{array}{l}\text { DAP } \\
(\mathbf{c m}) \\
\end{array}$ & $\begin{array}{c}\text { Altura } \\
(\mathbf{m})\end{array}$ & $\begin{array}{l}\text { DAP } \\
(\mathbf{c m}) \\
\end{array}$ & $\begin{array}{c}\text { Altura } \\
(\mathbf{m})\end{array}$ & $\begin{array}{l}\text { DAP } \\
(\mathbf{c m})\end{array}$ \\
\hline Valor Mínimo & 6,0 & 7,96 & 2,70 & 4,69 & 2,5 & 3,82 \\
\hline Valor Máximo & 10,0 & 42,63 & 6,30 & 18,82 & 6,0 & 24,68 \\
\hline Amplitude Total & 4,0 & 34,67 & 3,60 & 14,13 & 3,5 & 20,86 \\
\hline Mediana & 7,0 & 18,94 & 4,18 & 12,85 & 4,5 & 8,72 \\
\hline Média & 7,69 & 20,64 & 4,24 & 12,39 & 4,26 & 9,87 \\
\hline Desvio Padrão & 1,40 & 9,05 & 0,94 & 3,81 & 0,97 & 5,26 \\
\hline Erro Padrão & 0,31 & 2,02 & 0,21 & 0,85 & 0,22 & 1,21 \\
\hline $\begin{array}{l}\text { Coeficiente de } \\
\text { Variação }(\%)\end{array}$ & 18,19 & 43,86 & 22,25 & 30,77 & 22,75 & 53,33 \\
\hline Curtose & $-1,11$ & 0,45 & $-0,38$ & $-0,38$ & $-0,34$ & 2,70 \\
\hline $\begin{array}{l}\mathrm{N}^{\mathrm{o}} \text { mínimo de fustes } \\
\leq 1,3 \mathrm{~m}\end{array}$ & \multicolumn{2}{|c|}{1} & \multicolumn{2}{|c|}{1} & \multicolumn{2}{|c|}{1} \\
\hline $\begin{array}{l}\mathrm{N}^{\mathrm{o}} \text { máximo de } \\
\text { fustes } \leq 1,3 \mathrm{~m}\end{array}$ & \multicolumn{2}{|c|}{3} & \multicolumn{2}{|c|}{18} & \multicolumn{2}{|c|}{16} \\
\hline $\begin{array}{l}\mathrm{N}^{\circ} \text { médio de fustes } \\
\leq 1,3 \mathrm{~m}\end{array}$ & \multicolumn{2}{|c|}{1,3} & \multicolumn{2}{|c|}{9,7} & \multicolumn{2}{|c|}{5,3} \\
\hline
\end{tabular}

Para a área em estudo, os indivíduos da espécie $A$. colubrina obtiveram pouca variação para o parâmetro altura das árvores, atingindo entre 6 a 10m e média 7,7m, embora para os dados de DAP, foi verificado uma maior amplitude, com valores 
compreendidos entre 7,96 e 42,63cm e média de 20,64cm (Tabela 1), essa maior amplitude foi confirmada pelo alto coeficiente de variação de 43,86\%. Possivelmente, a pouca variação em altura possa ser explicada pelo investimento inicial em crescimento primário da planta, fato que, futuramente tende a ser compensado pelo crescimento secundário. Em geral, as variações dos resultados são explicadas também pela heterogeneidade e complexidade encontrada nos ecossistemas naturais, bem como, a confirmação da recuperação da degradação dessa área através da regeneração natural, que a cerca de 50 anos está sendo preservada, com indivíduos da mesma espécie com diferentes idades, constatadas por meio da altura e DAP. Quanto ao fuste da mesma, é característica da espécie geralmente ser reto e cilíndrico, com pouca ou nenhuma bifurcação abaixo de 1,30m (Figura 2 B), onde constatou-se que apenas $20 \%$ dos indivíduos são bifurcados, e com no máximo três fustes.

As espécies $C$. nordestinum e M. tenuiflora, também foram semelhantes em altura e DAP. Com relação ao parâmetro altura, as mesmas variaram de 2 a $6 \mathrm{~m}$ e valores médios, praticamente, iguais de 4,24 e 4,26m (Tabela 1). O DAP, também apresentou as maiores variações, com valores entre 4,69 e 18,82 cm para a $C$. nordestinum e 3,82 a 24,68cm para a M. tenuiflora, porém, apesar da diferença quanto à amplitude total dos dados de DAP, as médias ficaram muito próximas de 12,89 e 9,87cm, respectivamente (Tabela 1). Na Tabela 1 estão organizados também os dados sobre a bifurcação dos fustes destas espécies, onde verificou-se um número elevado de indivíduos com fustes a abaixo de 1,30m de altura, onde $95 \%$ dos indivíduos de $C$. nordestinum e $85 \%$ de $M$. tenuiflora se bifurcaram.

Os valores relacionados às características dendrométricas dos indivíduos amostrados das três espécies estudadas estão de acordo com as informações também mencionadas por outros autores em áreas de caatinga (CALIXTO JÚNIOR et al., 2011; SILVA et al., 2016; CAVALCANTI et al., 2020).

Considerando que a maioria das espécies da Caatinga permanece boa parte do ano sem folhas, por serem espécies caducifólias, assim, como já relatadas para as espécies $C$. nordestinum e $M$. tenuiflora, e também por não florescerem durante todo ano, outras características macromorfológicas das árvores como o fuste e casca, tornam-se muito importantes para o reconhecimento em campo.

A espécie A. colubrina possui fuste reto e de forma cilíndrica (Figura 2 C) e, em geral, a base se desenvolve sem saliências (reta) e com raízes subterrâneas (Figura 2 A). 
A casca externa (ritidoma) é acinzentada e com fissuras longitudinais como estrias, de textura áspera e presença de órgãos pungentes (acúleos), a casca interna (viva), por vezes, é de cor amarelada, com ausência de exsudatos após corte e odor característico de madeira (Figura 2 A a C). De acordo com Martins et al. (2020), a referida espécie é reconhecida pela sua contribuição para a indústria de curtume da região nordeste do Brasil devido ao teor de tanino encontrado na casca do fuste (13,95\%) (PAES et al., 2010).

Figura 2 - Aspectos macromorfológicos do fuste e da casca de indivíduos adultos das espécies Anadenanthera colubrina (Vell.) Brenan, Cenostigma nordestinum Gagnon \& G. P. Lewis e Mimosa tenuiflora (Willd.) Poir, ocorrentes em fragmento de Caatinga, Paraíba, Brasil.

Já o fuste de C. nordestinum, como descrito acima, se desenvolve na maioria dos indivíduos de forma ramificada, retos e/ou inclinados, e raízes subterrâneas (Figura 2 D). A casca do fuste desta espécie exibe características especificas que facilitam seu reconhecimento em campo e, possivelmente, o caráter mais marcante seja o desprendimento natural em placas grandes da casca morta (ritidoma), que possui coloração cinza claro, de aspecto áspero e presença de lenticelas (pontuações brancas) (Figura 2 F). No período de menor precipitação (julho a dezembro), o processo de desprendimento das placas da casca morta é tão intenso que o solo próximo à árvore fica parcialmente encoberto pelas mesmas (Figura 2 E). A casca interna (viva) apresenta uma variação na coloração desde esbranquiçada a amarelada, de textura levemente áspera e pulverulenta, ausência de exsudato e odor (Figura 2 F).

A M. tenuiflora também possui fuste ramificado na maioria dos indivíduos, retos e/ou levemente inclinados, sem saliências na base e repletos de espinhos pontiagudos, além de raízes subterrâneas (Figura 2 G). Essas características são muito semelhantes às da espécie $C$. nordestinum, porém, as outras características morfológicas das folhas, estruturas reprodutivas e cascas as diferenciam. Nos meses de maior escassez de água, os aspectos macromorfológicos da casca são imprescindíveis para diferenciação em campo das duas espécies. A casca morta (ritidoma) da M. tenuiflora possui uma coloração variando de amarronzada a castanha escura, com textura de áspera ou reticulada variando com diâmetro do ramo, desprendendo-se através de fissuras longitudinais (Figura $2 \mathrm{H}$ ). A casca viva (interna) apresenta coloração avermelhada e após o corte libera gotículas diminutas de exsudações, possivelmente, resina (Figura 2 I).

A espécie A. colubrina possui folhas de filotaxia alterna e são recompostas bipinadas (Figura 3 A), de consistência herbácea e superfície lisa, apresentando considerável variação no tamanho do limbo foliar com valores entre 11 e $24 \mathrm{~cm}$ de comprimento e 5 a $11 \mathrm{~cm}$ de largura, e pecíolo com média de $2 \mathrm{~cm}$ de comprimento. Com folíolos são lineares e paripenados, opostos dísticos e glabros, variando entre 13 a 28 pares e comprimento médio de $5 \mathrm{~cm}$. Os folíolos são também multifoliolados, com foliólulos que se dispõem de forma oposta, com cerca de 39 a 78 pares dos mesmos e vaiando entre 3 a $5 \mathrm{~mm}$ de comprimento e com bordas inteiras. Quanto às faces, as mesmas são concoloras, pois tanto a face adaxial quanto abaxial possui cores semelhantes (verdes) (Figura 3 B e C). 
Figura 3 - Aspectos macromorfológicos de ramos e folhas de Anadenanthera colubrina (Vell.) Brenan, Cenostigma nordestinum Gagnon \& G.P. Lewis e Mimosa tenuiflora (Willd.) Poir, coletados indivíduos adultos em fragmento de Caatinga, Paraíba, Brasil.


As folhas da $C$. nordestinum são compostas, imparipenadas, pecioladas $2,5 \mathrm{~cm}$, raque medindo de $7-15 \mathrm{~cm}$ de comprimento e $9-16 \mathrm{~cm}$ largura, e se dispõem nos ramos de forma alterna (Figura 3 D). Cada raque é composta em média por cinco folíolos, porém, foram observadas com até sete, os mesmos são opostos, variam em comprimento $5-9 \mathrm{~cm}$, 
sendo os menores mais próximos ao pecíolo (Figura 3 D). Os foliólulos são em média 11 por folíolo, com $2,2 \mathrm{~cm}$ de comprimento, alternos, de consistência coriácea, formato obovado, margem inteira ou suavemente ondulada, nervação peninérvea, ápice arredondado e base obtusa, as duas faces possuem coloração semelhantes, face adaxial glabra, e face abaxial com pilosidade (Figura 3 F). Os foliólulos, quando macerados, exalam cheiro forte e desagradável, motivo pelo qual, foi atribuído o nome comum da espécie, catingueira.

As folhas da $M$. tenuiflora são recompostas, paripenadas, de filotaxia alterna, pecíolos variando de $0,7-1,9 \mathrm{~cm}$, raque de dimensões médias de 6,9 x 7,3cm. Os folíolos são opostos, com média de $3,5 \mathrm{~cm}$ de comprimento, de 8 a 10 pares por raque. Os foliólulos são pequenos 4-8 mm, dispostos de forma oposta, glabros, borda inteira, faces de cores semelhantes, contudo, mais verde mais brilhante na face adaxial (Figura $3 \mathrm{G} \mathrm{e}$ $\mathrm{H})$.

As flores da A. colubrina são pequenas, medindo 2 x $2 \mathrm{~cm}$, globosas, com muitos estames livres entre si, com coloração amarelo-esbranquiçadas, são reunidas em inflorescências axilares ou terminais, trímero ou pentâmero, saindo da mesma inserção e ao longo do comprimento dos ramos finos. Apresentam simetria actinomorfa, diclamídeas e pediceladas (2cm) (Figura 4 A e B). 
Figura 4 - Aspectos macromorfológicos da inflorescência de Anadenanthera colubrina (Vell.) Brenan, Cenostigma nordestinum Gagnon \& G.P. Lewis e Mimosa tenuiflora (Willd.) Poir, coletadas de indivíduos adultos em fragmento de Caatinga, Paraíba, Brasil.
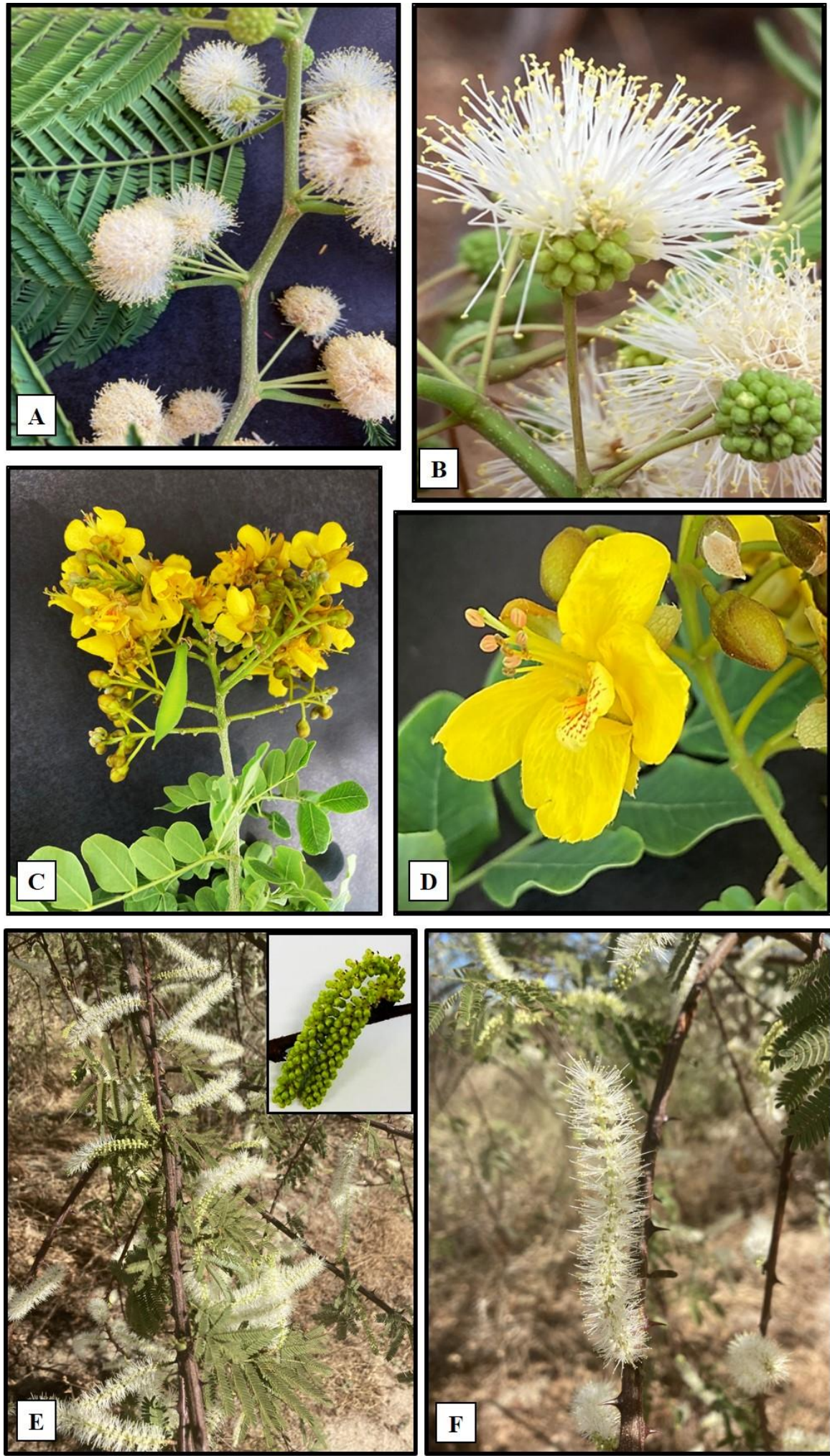
Com relação às flores da $C$. nordestinum, as mesmas são vistosas; dispostas em panículas terminais curtas; zigomorfas; completas, ou seja, possui os verticilos protetores e os verticilos reprodutores; pediceladas; cálice dialissépalo, pentâmero de coloração esverdeada; a corola apresenta pétalas livres entre si (dialipétala), coloração amarela (ricas em carotenóides), geralmente, pentâmera, ocasionalmente, ocorre flores com uma pétala central de menor tamanho, se destacando com pontuações de coloração alaranjada (Figura $4 \mathrm{C}$ e D). Possui um androceu diplostêmone, ou seja, o número de estames é dobro do número de pétalas, no caso, 10 estames livres entre si (dialistêmone) (Figura 4 D), e antera rimosa. Do carpelo, o estilete e estigma são de fácil observação, encontram-se posicionado em meio aos estames, e o ovário é ínfero (Figura 4 D).

As flores da $M$. tenuiflora são brancas, sésseis, pequenas, actinomorfas e reunidas em inflorescência do tipo espiga axilar, apresentando uma média de 66 flores por espiga, com dimensões médias de 10,13 x 1,43 centímetros, podendo ocorrer de forma isolada ou pareada (Figura 4 E e F). As sépalas são unidas entre si (cálice gamossépalo) de coloração esverdeada. As pétalas também são unidas entre si (corola gamopétala), de cor branca. Os estames são em número de oito por flor, e livres entre si, com cerca de 36 estames em média, com anteras rimosas. Na figura $4 \mathrm{E}$, podem ser verificadas espigas pareadas com os botões florais fechados.

O fruto da A. colubrina é classificado como do tipo folículo, é derivado de um único ovário (simples), apresenta pericarpo seco, pedúnculo lenhoso, polispérmico 1-16 sementes, e em média 4,5 lóculos vazios (Tabela 2), abrem-se em uma das laterais quando maduros liberando as sementes (deiscentes), possui formato linear ou curvado, e margem sinuosa de acordo com a presença das sementes. Quando imaturos possuem coloração verde a avermelhada e superfície lisa e, quando maduros, coloração marrom avermelhada e superfície levemente rugosa (Figura 5 A e B). Os frutos coletados dessa espécie possuem uma de amplitude de 9,5-40,04cm em relação ao comprimento e em média $28,58 \mathrm{~cm}$, largura de $1,58 \mathrm{~cm}$ e $0,2 \mathrm{~cm}$ de espessura (Tabela 2 ). 
Figura 5 - Aspectos macromorfológicos de frutos e sementes de Anadenanthera colubrina (Vell.) Brenan, Cenostigma nordestinum Gagnon \& G.P. Lewis e Mimosa tenuiflora (Willd.) Poir, coletados de indivíduos adultos em fragmento de Caatinga, Paraíba, Brasil.
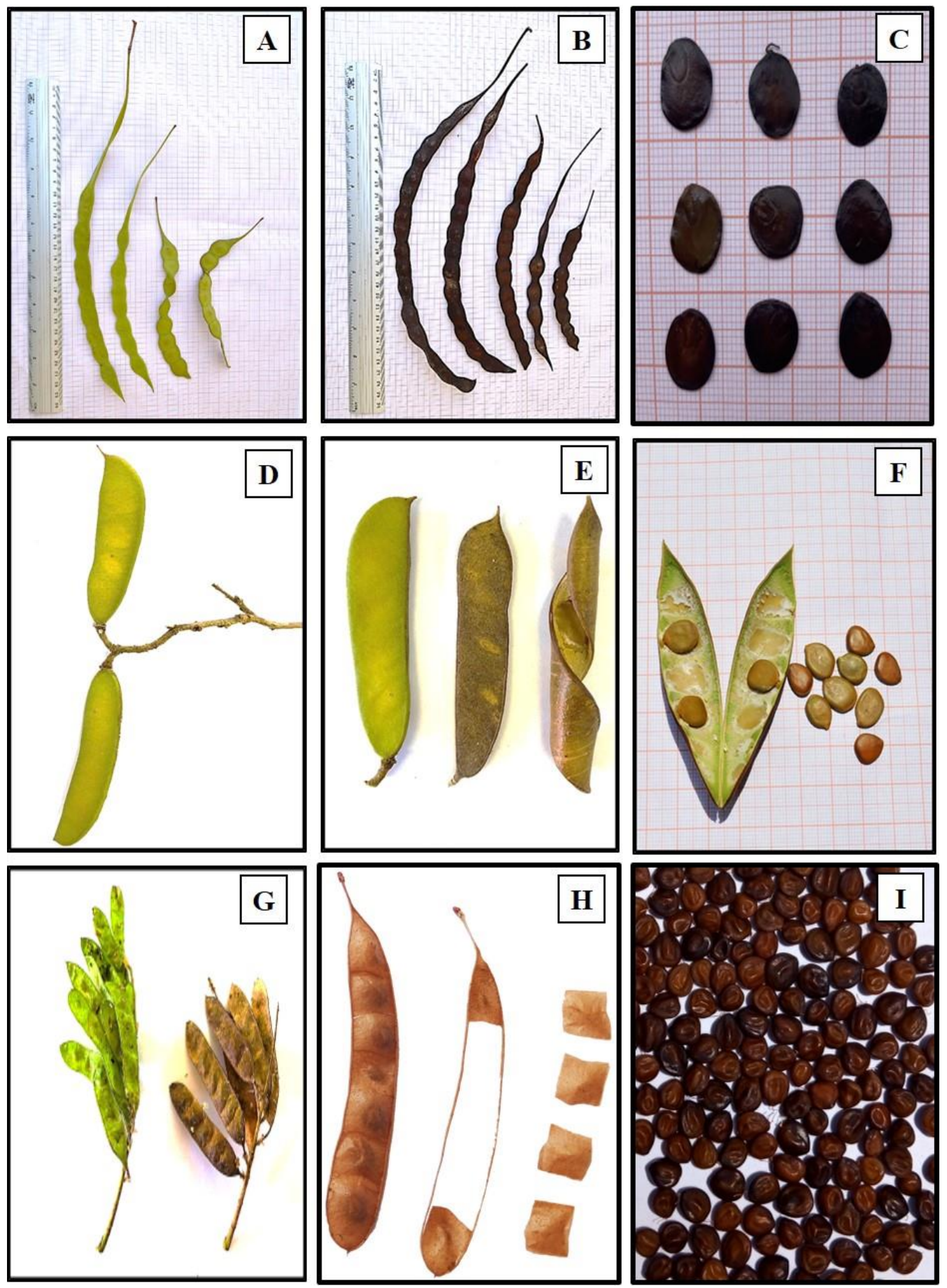

As sementes de A. colubrina são suborbiculares, formato arredondado, achatadas, coloração marrom escura, superfície lisa, dispersão autocórica e presença de marcante do pleurograma apical, o funículo, comumente, permanecem aderidos à semente após 
dispersão (Figura $5 \mathrm{C}$ ). Em geral, quanto ao tamanho as sementes não variam muito, medindo em média 1 x 1 x $0,1 \mathrm{~cm}$ de comprimento, largura e espessura (Tabela 3 ). Os frutos de $C$. nordestinum, são do tipo legume, simples, pericarpo de consistência seca e liso, pedúnculo curto e lenhoso, formato oblanceolado, reto e achatado, com margem inteira, base e ápice acuminado (Figura 5 D). Quando imaturo, a coloração é verde, passando para a coloração castanha, quando maduro (Figura 5 E).

Os frutos da $C$. nordestinum também são polispérmicos (1-6 sementes/fruto), deiscentes, com dispersão do tipo autocórica, ocorrendo de forma espontânea, devido à desidratação do pericarpo, o que leva a uma torção e ruptura brusca das valvas, deixandoas espiraladas (Figura 5 E), cujas sementes são lançadas ao chão. Suas dimensões variam de 4,7 a 10,6 cm de comprimento, de 1,5 a 2,4cm de largura e 0,1 a $0,4 \mathrm{~cm}$ de espessura (Tabela 2). As sementes, por sua vez, são de formato ovoide e achatadas e lisas, margens inteiras, e de coloração amarronzada (Figura 5 F). E suas dimensões são em média 1,2 x $0,8 \times 0,2 \mathrm{~cm}$ de comprimento, largura e espessura (Tabela 3 ).

Com relação à descrição morfológica dos frutos da espécie $M$. tenuiflora, os mesmos são do tipo craspédio, oriundos de apenas um ovário de uma flor (simples), seco, deiscente e pedúnculo lenhoso, porém, diminuto. Possui forma oblonga e reta, com margens inteiras, ligeiramente agudas no ápice e na base. Sua coloração varia da cor verde a marrom claro, de acordo com estágio de maturação (Figura 5 G). Quanto aos aspectos biométricos, os frutos coletados nesta área possuem em média $3,9 \mathrm{~cm}$ de comprimento, $0,77 \mathrm{~cm}$ de largura e $0,15 \mathrm{~cm}$ de espessura (Tabela 2). Quanto às sementes, são achatadas, pequenas, lisas, planas e de coloração castanha escura (Figura 5 I). Possui formato ovoide, margem inteira e com dimensões médias de $0,41 \mathrm{~cm}$ de comprimento, $0,31 \mathrm{~cm}$ de largura e $0,14 \mathrm{~cm}$ de espessura (Tabela 3 ). 
Tabela 2 - Estatística descritiva dos parâmetros relacionados à biometria de frutos e sementes provenientes de indivíduos adultos de Anadenanthera colubrina (Vell.) Brenan, Cenostigma nordestinum (Tul.) Gagnon \& G. P. Lewis e Mimosa tenuiflora (Willd.) Poir, ocorrentes em fragmento de Caatinga, Paraíba, Brasil.

\begin{tabular}{|c|c|c|c|c|c|c|c|c|}
\hline \multirow{3}{*}{$\begin{array}{l}\text { PARÂMETROS } \\
\begin{array}{l}\text { Tamanho da } \\
\text { amostra }\end{array}\end{array}$} & \multicolumn{8}{|c|}{ Frutos e sementes de Anadenathera colubrina (Vell.) Brenan } \\
\hline & \multicolumn{2}{|c|}{$\begin{array}{c}\text { Comprimento } \\
\text { (cm) }\end{array}$} & \multicolumn{2}{|c|}{$\begin{array}{c}\text { Largura } \\
\text { (cm) }\end{array}$} & \multicolumn{2}{|c|}{$\begin{array}{l}\text { Espessura } \\
\text { (cm) }\end{array}$} & \multirow{2}{*}{$\begin{array}{c}\begin{array}{c}\text { Número } \\
\text { semente/fruto }\end{array} \\
100\end{array}$} & \multirow{2}{*}{$\begin{array}{c}\begin{array}{c}\text { Lóculos } \\
\text { vazios }\end{array} \\
100\end{array}$} \\
\hline & 100 & 100 & 100 & 100 & 100 & 100 & & \\
\hline Valor Mínimo & 9,5 & 0,8 & 0,3 & 0,8 & 0,1 & 0,1 & 1,0 & 0,0 \\
\hline Valor Máximo & 40,4 & 1,3 & 2,0 & 1,3 & 0,4 & 0,2 & 16,0 & 14,0 \\
\hline Amplitude Total & 30,9 & 0,5 & 1,7 & 0,5 & 0,3 & 0,1 & 15,0 & 14,0 \\
\hline Mediana & 29,2 & 1,1 & 1,6 & 1,0 & 0,2 & 0,1 & 7,0 & 4,0 \\
\hline Média & 28,58 & 1,06 & 1,58 & 1,02 & 0,23 & 0,1 & 7,47 & 4,57 \\
\hline Desvio Padrão & 4,87 & 0,13 & 0,21 & 0,11 & 0,05 & 0,02 & 3,57 & 3,61 \\
\hline Erro Padrão & 0,49 & 0,01 & 0,02 & 0,01 & 0,01 & 0,0 & 0,36 & 0,36 \\
\hline $\begin{array}{l}\text { Coeficiente de } \\
\text { Variação (\%) }\end{array}$ & 17,06 & 12,29 & 13,48 & 10,67 & 23,59 & 16,65 & 47,74 & 78,94 \\
\hline Curtose & 1,98 & $-0,64$ & 11,94 & $-0,06$ & 0,49 & 29,9 & 0,36 & $-0,90$ \\
\hline \multirow{2}{*}{ PARÂMETROS } & \multicolumn{8}{|c|}{ Frutos e sementes de Cenostigma nordestinum (Tul.) Gagnon \& G. P. Lewis } \\
\hline & \multicolumn{2}{|c|}{$\begin{array}{c}\text { Comprimento } \\
(\mathrm{cm})\end{array}$} & \multicolumn{2}{|c|}{$\begin{array}{c}\begin{array}{c}\text { Largura } \\
(\mathrm{cm})\end{array} \\
\end{array}$} & \multicolumn{2}{|c|}{$\begin{array}{c}\text { Espessura } \\
(\mathbf{c m})\end{array}$} & $\begin{array}{c}\text { Número } \\
\text { semente/fruto }\end{array}$ & $\begin{array}{c}\text { Lóculos } \\
\text { vazios }\end{array}$ \\
\hline $\begin{array}{l}\text { Tamanho da } \\
\text { amostra }\end{array}$ & 100 & 100 & 100 & 100 & 100 & 100 & 100 & 100 \\
\hline Valor Mínimo & 4,7 & 0,9 & 1,5 & 0,6 & 0,2 & 0,1 & 1,0 & 0,0 \\
\hline Valor Máximo & 10,6 & 1,4 & 2,4 & 1,0 & 0,5 & 0,3 & 6,0 & 6,0 \\
\hline Amplitude Total & 5,9 & 0,5 & 0,9 & 0,4 & 0,3 & 0,2 & 5,0 & 6,0 \\
\hline Mediana & 6,9 & 1,2 & 2,0 & 0,8 & 0,3 & 0,2 & 2,0 & 2,0 \\
\hline Média & 6,95 & 1,17 & 1,95 & 0,83 & 0,29 & 0,18 & 2,9 & 2,3 \\
\hline Desvio Padrão & 1,08 & 0,1 & 0,17 & 0,07 & 0,08 & 0,05 & 1,5 & 1,4 \\
\hline Erro Padrão & 0,11 & 0,01 & 0,02 & 0,01 & 0,01 & 0,00 & 0,1 & 0,1 \\
\hline $\begin{array}{l}\text { Coeficiente de } \\
\text { Variação (\%) }\end{array}$ & 15,55 & 8,18 & 8,56 & 8,28 & 27,24 & 26,69 & 51,17 & 59,58 \\
\hline Curtose & 0,63 & 0,07 & 0,77 & 0,59 & $-1,00$ & 0,19 & $-0,9$ & $-0,07$ \\
\hline \multirow[b]{2}{*}{ PARÂMETROS } & \multicolumn{8}{|c|}{ Frutos e sementes de Mimosa tenuiflora (Willd.) Poir. } \\
\hline & \multicolumn{2}{|c|}{$\begin{array}{c}\text { Comprimento } \\
(\mathrm{cm})\end{array}$} & \multicolumn{2}{|c|}{$\begin{array}{c}\text { Largura } \\
(\mathrm{cm})\end{array}$} & \multicolumn{2}{|c|}{$\begin{array}{l}\text { Espessura } \\
(\mathrm{cm})\end{array}$} & $\begin{array}{c}\text { Número } \\
\text { semente/fruto }\end{array}$ & $\begin{array}{c}\text { Lóculos } \\
\text { vazios }\end{array}$ \\
\hline $\begin{array}{l}\text { Tamanho da } \\
\text { amostra }\end{array}$ & 100 & 100 & 100 & 100 & 100 & 100 & 100 & 100 \\
\hline Valor Mínimo & 2,6 & 0,3 & 0,6 & 0,2 & 0,1 & 0,1 & 0,0 & 0,0 \\
\hline Valor Máximo & 4,9 & 0,5 & 0,9 & 0,4 & 0,3 & 0,2 & 7,0 & 4,0 \\
\hline Amplitude Total & 2,3 & 0,2 & 0,3 & 0,2 & 0,2 & 0,1 & 7,0 & 4,0 \\
\hline Mediana & 3,8 & 0,4 & 0,8 & 0,3 & 0,2 & 0,1 & 4,0 & 0,0 \\
\hline Média & 3,9 & 0,41 & 0,77 & 0,31 & 0,15 & 0,14 & 3,46 & 0,6 \\
\hline Desvio Padrão & 0,4560 & 0,05 & 0,09 & 0,04 & 0,05 & 0,05 & 1,36 & 0,86 \\
\hline Erro Padrão & 0,0456 & 0,0 & 0,01 & 0,0 & 0,01 & 0,0 & 0,14 & 0,09 \\
\hline $\begin{array}{l}\text { Coeficiente de } \\
\text { Variação }(\%)\end{array}$ & 11,72 & 11,90 & 11,95 & 12,29 & 33,81 & 35,27 & 39,28 & 144,09 \\
\hline Curtose & 0,0039 & 0,75 & $-0,77$ & 2,64 & $-1,51$ & $-1,83$ & $-0,34$ & 2,70 \\
\hline
\end{tabular}




\section{Chave de Identificação Dendrológica}

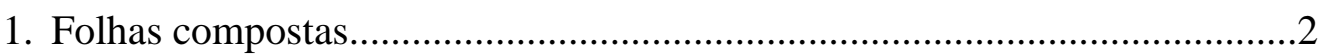

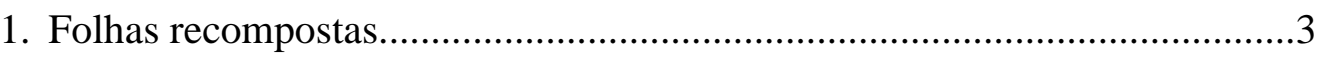

2. Casca se desprendendo em grandes placas, lenticelas visíveis; Folhas imparipenadas, foliolulos alternos, cheiro forte e desagradável (terebentina); Flores amarelas e vistosas; Fruto legume e formato oblanceolado Cenostigma nordestinum.

3. Casca externa acizentada. 4

3. Casca externa avermelhada .5

4. Fuste reto e cilíndrico; Folhas multifolioladas, folíolos lineares; Flores globosas, inflorescência axilar; Fruto folículo e formato encurvado; Sementes suborbiculares. Anadenathera colubrina

5. Casca interna avermelhada; exsudação do tipo resina; Flores sésseis e inflorescência do tipo espiga axilar; Fruto craspédio de coloração marrom claro.

Mimosa tenuiflora

\section{CONCLUSÕES}

- As folhas e estruturas reprodutivas, apesar de serem importantes na identificação, não permanecem durante todos os meses do ano nas árvores das espécies estudadas, pois estão correlacionadas com os fatores climáticos;

- Para as três espécies estudadas, os aspectos macromorfológicos do fuste, da copa e da casca são mais indicados para a identificação em campo, já que estão presentes durante todos os meses do ano, independente do período chuvoso ou seco, além de possuírem características simples e rápidas de serem observadas.

\section{AGRADECIMENTOS}

O presente trabalho foi realizado com apoio do CNPq, Conselho Nacional de Desenvolvimento Científico e Tecnológico - Brasil, pelo programa PIBIC/CNPq-UFCG. 


\section{REFERÊNCIAS}

APG (Angiosperm Phylogeny Group). An update of the Angiosperm Phylogeny Group classification for the orders and families of flowering plants: APG IV. Botanical Journal of the Linnean Society, v. 181, p. 1-20 2016.

CÂNDIDO, J. B.; VIANA, R. H. O.; MORAIS, I. G.; AMORIM, M. V. M.; SOUZA, P. B. Chave de identificação dendrológica das espécies mais comuns de uma área de Cerrado Sensu Stricto, Gurupi, Tocantins. Ciência Florestal, v. 29, n. 1, p. 347-362, 2019.

CALIXTO JÚNIOR, J. T.; DRUMOND, M. A.; JÚNIOR, F. T. A. Estrutura e distribuição espacial de Mimosa tenuiflora (Willd.) Poir; em dois fragmentos de caatinga em Pernambuco. Revista Caatinga, v. 24, n. 2, p. 95-100, 2011.

CARVALHO, P. E. R. Angico-branco. EMBRAPA: Série Técnica 56. Colombo, PR, 2002.

CAVALCANTI, L. C. DE S.; SANTOS, K. P.; SANTOS, D. S. S. Estrutura, funcionamento e uso de geossistemas locais no semiárido brasileiro. Boletim de Geografia, v. 37, n. 2, p. 218-234, 2020.

CLIMATE-DATA.ORG. Disponível em: https://pt.climate-data.org/america-dosul/brasil/paraiba/patos-42575/>. Acesso em: 11 jun. 2020

DUTRA, V.F.; Morales, M.; Jordão, L.S.B.; Borges, L.M.; Silveira, F.S.; Simon, M.F.; Santos-Silva, J.; Nascimento, J.G.A.; Ribas, O.D.S. 2020. Mimosa in Flora do Brasil 2020. Jardim Botânico do Rio de Janeiro. Disponível em: <http://reflora.jbrj.gov.br/reflora/floradobrasil/FB18874>. Acesso em: 09 mar. 2021

EMBRAPA. Sistema brasileiro de classificação de solos. 3 ed. Rio de Janeiro: Centro Nacional de Pesquisas de Solos, 2013. 353 p.

GAEM, P.H. 2020. Cenostigma in Flora do Brasil 2020. Jardim Botânico do Rio de Janeiro. Disponível em: <http://reflora.jbrj.gov.br/reflora/floradobrasil/FB606076>. Acesso em: 09 mar. 2021

MARCHIORI, J.N.C. Elementos de dendrologia. Santa Maria: UFSM, 1995. 163p.

MARCHIORI, J. N. C. Elementos de dendrologia. $2^{\text {a }}$ ed. Santa Maria: UFSM, 2004. 176p.

MARTINS, G. M. C.; SILVA, J. M.; SILVA, R. B.; SILVA, H. C. H.; SILVA, J. V.; MOURA, F. B. P. Potencial alelopático de extratos aquosos de Anadenanthera colubrina (vell.) Brenan sobre a germinação da alface. Revista Ouricuri, v.10, n.1. p.001-010, 2020. 
MORIM, M.P. 2020. Anadenanthera in Flora do Brasil 2020. Jardim Botânico do Rio de Janeiro. Disponível em: <http://reflora.jbrj.gov.br/reflora/floradobrasil/FB18071〉. Acesso em: 09 mar. 2021

MINISTÉRIO DO MEIO AMBIENTE (MMA). Caatinga. Disponível em:

< https://www.mma.gov.br/biomas/caatinga >. Acesso em: 11 jun. 2020

PAES, J. B.; SANTANA, G. M.; AZEVEDO, T. K. B.; MORAIS, R. M.; CALIXTO JÚNIOR, J. T. Substâncias tânicas presentes em várias partes da árvore angicovermelho (Anadenanthera colubrina (Vell.) Brenan. var. cebil (Gris.) Alts.). Scientia. Forestalis, v. 38, n. 87, p. 441-447, 2010.

REDE DE MANEJO FLORESTAL DA CAATINGA - RMFC: Protocolo de medições de parcelas permanentes. Comitê Técnico Científico. - Recife: Associação Plantas do Nordeste, 21p; 2005.

SOARES, C. P. B.; PAULA NETO, F.; SOUZA, A. L. Dendrometria e inventário florestal. Viçosa, MG: Universidade Federal de Viçosa, 2006. 276p.

SILVA, A. C. C.; PRATA, A. P. N.; MELLO, A. A. Florística, fitossociologia e caracterização sucessional em um remanescente de Caatinga em Sergipe. Gaia Scientia, v. 10, p. 01-14, 2016. 